\title{
SOURCES OF VARIABILITY IN AGGREGATION AND SEX RATIOS OF CRATAERINA MELBAE (DIPTERA: HIPPOBOSCIDAE) AMONG ADULT COLONIAL ALPINE SWIFTS
}

\author{
José L. Tella and Roger Jovani* \\ Department of Applied Biology, Estación Biológica de Doñana, CSIC, Avda. M. Luisa s/n, Pabellón del Perú, 41013 Sevilla, Spain
}

\begin{abstract}
Aggregation of Crataerina melbae flies on breeding adult alpine swifts (Apus melba) was low when compared with other host-parasite systems and varied with sampling date, year, and sex of the flies. Generalized linear models were performed to ascertain which factors, extrinsic and/or intrinsic to the host, explained variability in the number of louse flies present on a single host, i.e., abundance. Overall abundance was unrelated to any host characteristic but varied slightly among years. Abundance of female flies varied among years, but also with date of sampling, the number of females increasing as the breeding season advanced. In contrast, abundance of males decreased as the season progressed, independently of host characteristics. Despite these different patterns, the number of flies of each sex on a given host was strongly intercorrelated. These results suggest that mate attraction may explain aggregation patterns in this louse fly species. Overall sex ratio of louse flies did not differ from unity. However, the proportion of males decreased during the breeding season, as a consequence of the opposite sex-related seasonal patterns in parasite abundance. Sex-ratio variability was not related to host characteristics or to infrapopulation sizes.
\end{abstract}

Since Hamilton and Zuk (1982) raised the importance of parasites in the evolutionary biology of their hosts, much has been done on bird-parasite interactions (Clayton and Moore, 1997). However, some researchers have claimed that a good knowledge of the biology and ecology of parasites is needed before attempting to elucidate their relationships with birds and how these can drive bird evolution (Clayton, 1991; Poulin, 1995; John, 1997). This criticism may apply in the case of louse flies (Diptera: Hippoboscidae), which are blood-sucking arthropods widespread among birds and mammals (Marshall, 1981a). Whereas recent studies have focused on the potential effects of louse flies on birds (Senar et al., 1994; Lee and Clayton, 1995; Tella et al., 1995; Tompkins et al., 1996; Saino et al., 1998), little is known about many aspects of the biology and population dynamics of these parasites (Marshall, 1981a).

Louse flies are viviparous species that couple their breeding cycles to those of their avian hosts. The pupae are usually deposited in the host's nest after completion of the larval stage inside the female fly, overwintering there as diapausing pupae until the host's next breeding season. Emerged flies rapidly reach maturity and use the adult hosts for feeding, mating, and copulation (Marshall, 1981a). Most studies on louse flies have simply reported prevalence data on adult birds (e.g., McClure, 1984). The few that dealt with frequency distributions among hosts showed aggregation, i.e., most birds had none or few flies, whereas a few had many (Marshall, 1981a; Lee and Clayton, 1995). However, nothing is known regarding the nature of those factors that promote aggregated distributions in louse flies parasitizing adult birds.

Apart from the spatial and temporal heterogeneity in the breeding cycles of the parasites, differences in the exposure, behavior, immunity, and other characteristics of individual hosts such as their sex and age have been variously invoked to explain the aggregation of parasites (Marshall, 1981a; Poulin, 1998). The variability in the patterns of distribution of parasites not only influences their evolutionary and population ecology (Jaenike, 1996; Poulin, 1998) but also may differentially affect

Received 3 September 1999; revised 22 February 2000; accepted 22 February 2000.

* Department of Biologia Animal, Vertebrats, Universitat de Barcelona, Diagonal 645, 08028 Barcelona, Spain. host fitness (Poulin and Vickery, 1993) and the dynamics of the host-parasite systems (Hudson and Dobson, 1997).

The distribution and aggregation of parasites among hosts is a dynamic product of processes that are not constant in time (Poulin, 1998). Furthermore, if these processes differentially affect male and female parasites, the frequency of encounter with potential mates is likely to be uneven (Poulin, 1998). It could explain why sex ratios of louse flies on adult birds are frequently unbalanced (Marshall, 1981b), a pattern for which there is no clear explanation (Marshall, 1981a). One possible reason is that sex ratios would be biased because of the time of sampling (Marshall, 1981a). Hutson (1981) reported a decrease in the proportion of male Crataerina pallida on adult European swifts (Apus apus) as the host breeding season advanced but was unable to ascertain whether it was due to a decline in the number of males, an increase in females, or both.

Crataerina melbae is a common parasite of the colonial alpine swift (Apus melba) (Tella et al., 1998). Crataerina flies are flightless, thus limiting their movements among hosts, and have a single generation each year (Marshall, 1981a). In the present paper, we first assess the degree of aggregation of $C$. melbae on breeding adult alpine swifts and its variability in relation to date and/or year of sampling, the number of hosts sampled, and gender of the flies. Then, we examined potential factors that could explain the variability in abundance (sensu Bush et al., 1997) of louse flies among hosts, which could explain variation in aggregation (Poulin, 1998). We considered several factors, i.e., host sex, age, size, mass, body condition, and molt stage, that could affect its exposure, susceptibility, or both, to the parasites, in addition to 2 factors extrinsic to the host, i.e., year and date of sampling, that could affect the overall louse fly abundance (see Marshall, 1981a). Additionally, because louse flies mate in the body of their hosts (Marshall, 1981a), we considered the possibility that the aggregation of flies of 1 sex could depend on the number of flies of the opposite sex on a given host. Finally, we determined whether parasite sex ratios varied among sampling dates and years and whether these biases are due to host factors or to different aggregation patterns for male and female louse flies. Relationships between infrapopulation sizes (sensu Bush et al., 1997) and its sex ratios were also examined that could then be related to local 
mate or local resource competition (Rózsa et al., 1996) among flies.

\section{MATERIALS AND METHODS}

The alpine swift is an aerial, insectivorous apodiforme bird weighing ca. 90 g. It is a trans-Saharian migrant that spends most of its lifetime in flight, only landing for breeding purposes. Because of its cliff-nesting breeding habits and its scarcity, many aspects of its biology are poorly known (Cramp, 1985). In the colony under study (Teruel, NE Spain; Tella et al., 1998) there are about $400-500$ breeding alpine swifts nesting inside crevices within a chasm $100 \mathrm{~m}$ deep, making the access to the nests very difficult. Crataerina melbae seems to be highly hos specific (Tella et al., 1998), parasitizing alpine swifts in our colony and in other areas of Europe (Roulin et al., 1998) and South Africa (C. Collins and J. L. Tella, unpubl. obs.).

Breeding adult alpine swifts were trapped by means of a handheld mist net maintained by 2 persons in horizontal position close to the ground at the edge of the chasm. The net was raised when a bird tried to enter or leave the colony, intercepting its flight. Captures were made during 2-day trapping sessions conducted from early July to early August, coinciding with the chick-rearing stage, over a 4-yr period (1991, 1992, 1998, 1999). All birds were kept individually in cloth bags, banded, and measured. Swifts were aged as second-year birds or adults (at least 3 yr old) following Cramp (1985). In 1998, a drop of blood was collected from the brachial vein of 50 alpine swifts for molecular sexing using the primers 2945F, cfR, and 3224R as described by Ellegren (1996). Because we did not know the sex of the rest of the swifts, we also measured the length of the fork (distance between the innermos and the outermost tail feathers), which is a sexually dimorphic character for this species (J. L. Tella and R. Jovani, unpubl. obs.). We used wing length as an indicator of body size, and the residuals of log-body mass on log-wing length in a least-square regression as an index of body condition. Molt stage was determined as the number of primary flight feathers remaining to be replaced (Jenni and Winkler, 1994).

Alpine swifts were systematically searched for louse flies by blowing the feathers of the whole body during a 5-10-min period. This visual method has been extensively used to collect louse flies (e.g., Hutson, 1981; McClure, 1984) and is particularly effective for C. melbae, because it is a large louse fly species and easy to detect (Tella et al., 1998). The search time was flexible in order to be sure that all flies were collected. Losses of flies during netting are unlikely because swifts were kept individually in cloth bags immediately after being caught. Cloth bags were also checked to avoid missing flies. All flies were captured and stored (in 70\% ethanol) in separate tubes for each host. Flies were subsequently sexed in the laboratory by examining genitalia (Theodor and Oldroyd, 1964).

To examine the distribution of louse flies within the host population, we obtained the parameter $k$ of the negative binomial distribution, which is inversely proportional to the degree of aggregation (Shaw et al., 1998). Although other indices of aggregation are available (Poulin, 1998), we chose $k$ because different indices offer correlated results (Miklisova and Stanko, 1997) and because $k$ is more extensively used, thus facilitating further interspecific comparisons (e.g., Shaw et al., 1998). The $k$ parameter was calculated using the maximum likelihood method by means of a macro provided by Crawley (1993). The $k$-values were separately obtained for each trapping session, year, and sex of flies, and also for pooled data. Values of $k$ approaching 0 indicate highly aggregated distributions, and $G$-tests for goodness of fit were used to test whether or not these distributions could be described adequately by the negative binomial model (Crawley, 1993).

Distribution of louse flies among hosts could be influenced by factors such as year, date, and characteristics of individual hosts (Marshall, 1981a; McClure, 1984; Tella et al., 1995) that potentially covary, thus bringing the validity of univariate tests into question (see Tella et al., 1998). Therefore, we used generalized linear models (GLMs) to assess simultaneously which explanatory variables or their interactions better explain the variability in louse fly abundance, i.e., the number of flies present on a single host, including unparasitized birds (Bush et al., 1997), that may cause variability in aggregation patterns. The number of males, females, and total number of louse flies present on each swift were used as response variables in 3 different models. Two kinds of potential explanatory variables were analyzed: variables extrinsic to the host (year and date of the trapping session), and variables related to the individual host (age, sex, and the sex-related fork length, wing length as a measure of body size, body mass, body condition, and molt stage of each bird). All these variables have been proposed for explaining variability in ectoparasite loads among birds (Marshall, 1981a; Poulin, 1998). Because the number of flies on each bird can be considered as a count, and its distribution among hosts did not always fit a negative binomial (see Results), we specified a Poisson error and a logarithm link function in these models (Crawley, 1993). Nonetheless, we determined whether the final models presented large overdispersion, i.e., residual deviance/residual $\mathrm{df}>1.5$, indicating that a negative binomial distribution of errors would better fit the data (Crawley, 1993).

Deviations from unity in the proportion of male to female louse flies were tested using goodness-of-fit tests (Zar, 1984). For assessing which factors better explain the variability in the sex ratio of the flies, we also used GLM modeling, considering the same potential explanatory variables indicated above, as well as the total number of flies in the infrapopulation, i.e., the number of flies on a parasitized host (Bush et al., 1997). To analyze the proportion of sexes, a GLM with binomial error and a logistic link function is the most appropriate statistical tool (Crawley, 1993). Instead of using the percentage of male louse flies present in a single bird, which does not include information on the sample size (number of flies) from which the proportion was estimated, this procedure uses the number of males as a response variable and the number of flies (males + females) present as the binomial denominator (Crawley, 1993). All GLMs were fitted with GLIM software (Crawley, 1993), following the forward stepwise branching modeling procedure (Tella et al., 1999). All $P$-values refer to 2 -tailed tests.

\section{RESULTS}

\section{Louse-fly aggregation}

Most alpine swifts $(70.8 \%, \mathrm{n}=233)$ were parasitized by $C$. melbae, the abundance ranging from 0 to 31 flies per bird. Louse flies appeared to be aggregated among hosts when considering pooled data (Fig. 1). The obtained $k$ parameters indicated a slight aggregation both for the total number of louse flies $(k=0.81)$ and for males and females separately $(k=0.78$ and $k=0.73$, respectively), with these distributions being well described by a negative binomial distribution ( $G$-test of goodness of fit, all $P>0.05)$. However, the degree of louse-fly aggregation varied between years, date of the trapping session, and sex of the flies (Table I). From 29 distributions, only 16 (55.2\%) were significantly aggregated, with the $k$ parameter ranging from 0.08 to values much higher than 1 (maximum $k$ $=2.58$ ). However, the only $k$ value approaching 0 , which indicates a high parasite aggregation, was provided by only 2 louse flies distributed among 12 swifts. Patterns of parasite aggregation also differed between sexes for single trapping sessions and years (Table I). Variability in parasite aggregation does not seem to be related to the number of hosts sampled for each subset of data because $k$-values are not correlated with sample sizes (Spearman correlation, $r_{s}=-0.04, P=0.98, \mathrm{n}$ $=32$ ). Correlations were not significant for males $\left(r_{s}=-0.15\right.$, $P=0.68, \mathrm{n}=10)$, females $\left(r_{s}=0.09, P=0.79, \mathrm{n}=11\right)$, nor for the total number of louse flies $\left(r_{s}=0.009, P=0.98, \mathrm{n}=\right.$ 11).

GLM models performed to ascertain which variables explained the observed variability in the abundance of louse flies showed different results for males, females, and pooled sexes (Table II). The number of louse-fly males present on a given swift increased as the number of female flies on the same bird increased and decreased as the breeding season advanced (Fig. 2a). This model explained $36.7 \%$ of the total deviance and did not show large data overdispersion (residual deviance/residual 


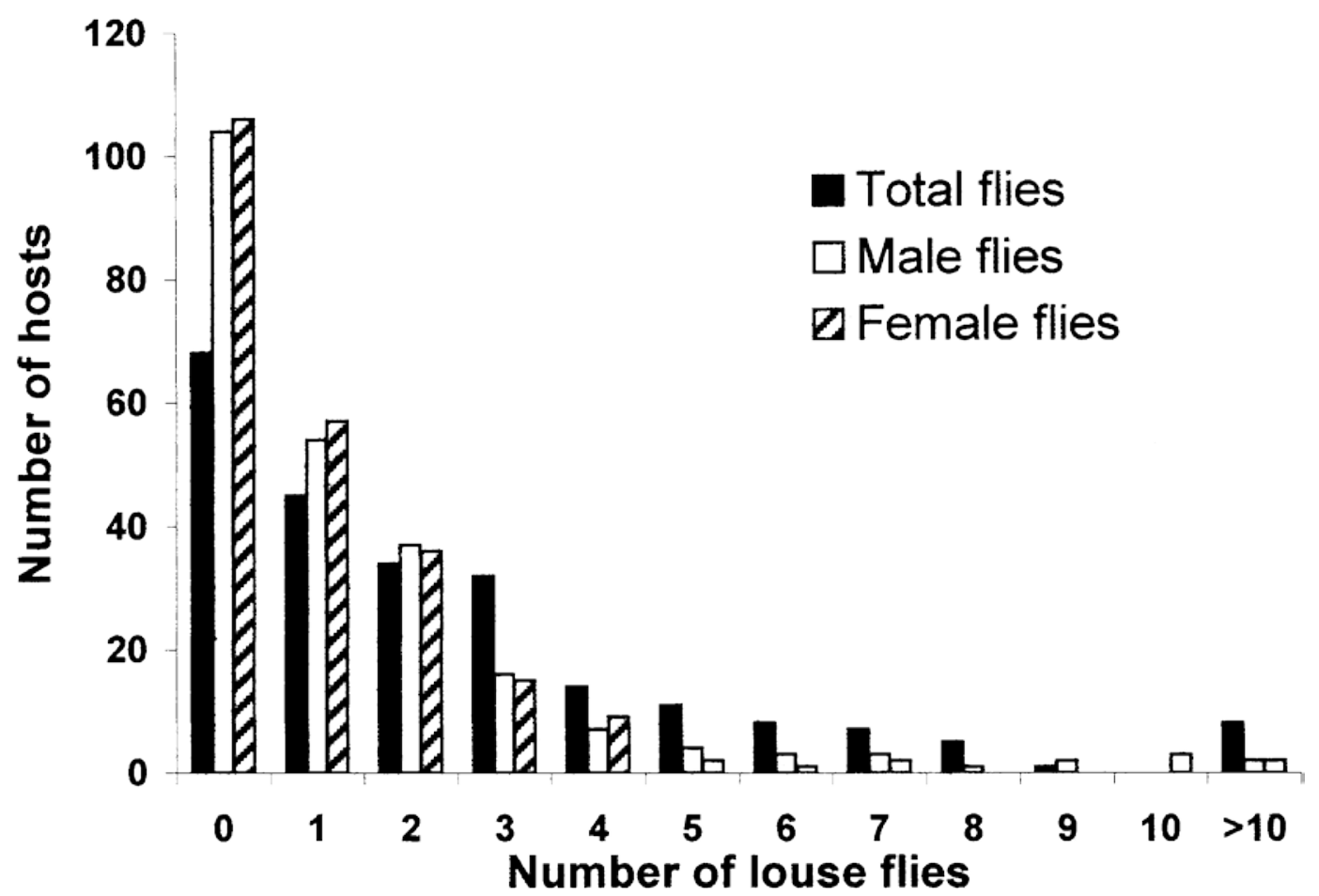

FiguRE 1. Distribution of Crataerina melbae of each sex (white bars, males; dashed bars:, females) and lumped sexes (black bars) among all adult alpine swifts (Apus melba) examined at a single colony during 1991, 1992, 1998, and 1999 ( $\mathrm{n}=233$ ). Note that often the number of hosts with a given number of flies, e.g., 0 flies, is lower than both the number of hosts with 0 male flies and the number of hosts with 0 female flies (i.e., some hosts hold 0 female flies but Š1 male, and vice versa).

$\mathrm{df}=1.32$ ). The number of female flies also increased with the number of flies of the opposite sex parasitizing the same bird, but, contrary to males, their numbers increased as the season advanced and also differed between years (Fig. 2b). The parameter estimates for years 1998 and 1999 were almost identical ( 0.38 and 0.39 , respectively). Therefore, we derived a simplified model by grouping both years (Table II) that was not significantly different from the first one (change in deviance $=0.7$, $\mathrm{df}=1, P>0.1$ ). This final model (Fig. 2b) explained $55.1 \%$ of the total deviance and did not indicate data overdispersion (residual deviance/residual $\mathrm{df}=0.79$ ).

Finally, the total number of louse flies (sexes pooled) parasitizing a given bird only varied between years $(P<0.005)$. However, the model obtained showed large data overdispersion (residual deviance/residual $\mathrm{df}=2.30$ ), suggesting that the data could be better described by a negative binomial distribution. Thus, we repeated the analyses using an adequate macro for negative binomial errors (Crawley, 1993). Qualitatively, the results were much the same as with the Poisson error, as year was the only variable entering in the model. The years 1991, 1998, and 1999 did not differ significantly (change in deviance $=1.72$, $\mathrm{df}=2, P>0.1$ ) and thus were grouped with the final model (Table II) explaining $5.5 \%$ of the total deviance and indicating no data overdispersion (residual deviance/residual df $=1.15)$.

\section{Sex ratios of louse flies}

Overall, $50.97 \%$ of the collected louse flies $(n=620)$ were males. This sex ratio did not differ from unity (goodness-of-fit test, $\left.y^{2}=0.23, P=0.63\right)$. However, sex ratios varied from significantly skewed to males to significantly skewed to females, depending on the trapping sessions and years considered (Table I). The GLM performed for analyzing sources of variability in the sex ratio of louse flies showed that the proportion of male flies present in a bird was related only to the date of trapping, with this proportion decreasing as the breeding season advanced. The fitted values for this model lead to the following function for the linear predictor (LP) of the logistic equation: $\mathrm{LP}=0.854(\mathrm{SE} 0.184)-0.053(\mathrm{SE} 0.010) \times$ date of trapping. This model accounted for $12 \%$ of the original deviance and did not suffer data overdispersion (residual deviance/residual $\mathrm{df}=$ 1.19).

\section{DISCUSSION}

\section{Overall louse-fly aggregation}

Our results show that louse flies are aggregated among adult alpine swifts, in accordance with the most common pattern for metazoan parasite populations (Poulin, 1998). However, the degree of aggregation is much lower than those found for other parasite species (Shaw et al., 1998). This fact may be related to life history traits of alpine swifts, such as their colonial breeding system. In contrast to the low prevalence of louse flies reported for birds, usually 0-20\% (e.g., McClure, 1984; Tella et al., 2000), up to $86 \%$ of adult alpine swifts are parasitized by C. melbae (Tella et al., 1998), this prevalence being the highest recorded for any avian species. Shaw et al. (1998), in an interspecific comparative study, showed a negative correla- 
TABLE I. Parameter of aggregation $k$ for the distribution of louse flies (sample sizes below) among alpine swift hosts in different years and trapping sessions (denoted as 1 or 2).* Sex ratios for each sample are expressed as the percentages of males.

\begin{tabular}{|c|c|c|c|c|c|}
\hline Year & $\begin{array}{l}\text { Num- } \\
\text { ber of } \\
\text { swifts }\end{array}$ & Females & Males & Total & $\begin{array}{c}\% \\
\text { Males }\end{array}$ \\
\hline & & & . & & \\
\hline & & $\mathrm{n}=25$ & $\mathrm{n}=51$ & $\mathrm{n}=76$ & \\
\hline 1991 (2) & 12 & $\begin{array}{l}k=\mathbf{0 . 0 8 5} \\
\mathrm{n}=2\end{array}$ & $\mathrm{n}=0$ & $\begin{array}{l}k=\mathbf{0 . 0 8 5} \\
n=2\end{array}$ & - \\
\hline Total 1991 & 39 & $\begin{array}{l}k=\mathbf{0 . 4 6 9} \\
\mathrm{n}=27\end{array}$ & $\begin{array}{l}k=\mathbf{0 . 5 5 9} \\
\mathrm{n}=51\end{array}$ & $\begin{array}{l}k=\mathbf{0 . 7 2 3} \\
\mathrm{n}=78\end{array}$ & $65.3 \dagger$ \\
\hline 1992 (1) & 45 & $\begin{array}{l}k=\mathbf{0 . 6 9 6} \\
\mathrm{n}=72\end{array}$ & $\begin{array}{l}k=\mathbf{0 . 6 4 2} \\
\mathrm{n}=87\end{array}$ & $\begin{array}{l}k=\mathbf{0 . 6 6 2} \\
\mathrm{n}=159\end{array}$ & 54.7 \\
\hline 1992 (2) & 20 & $\begin{array}{l}k=2.582 \\
\mathrm{n}=50\end{array}$ & $\begin{array}{l}k=1.376 \\
\mathrm{n}=48\end{array}$ & $\begin{array}{l}k=1.641 \\
\mathrm{n}=98\end{array}$ & 48.9 \\
\hline Total 1992 & 65 & $\begin{array}{c}k=1.016 \\
\mathrm{n}=122\end{array}$ & $\begin{array}{l}k=\mathbf{0 . 8 0 5} \\
\mathrm{n}=135\end{array}$ & $\begin{array}{l}k=\mathbf{0 . 8 5 6} \\
\mathrm{n}=257\end{array}$ & 52.5 \\
\hline Total 1998 & 61 & $\begin{array}{l}k=2.233 \\
\mathrm{n}=50\end{array}$ & $\begin{array}{l}k=1.619 \\
\mathrm{n}=66\end{array}$ & $\begin{array}{l}k=1.423 \\
\mathrm{n}=116\end{array}$ & 56.8 \\
\hline 1999 (1) & 38 & $\begin{array}{l}k=1.089 \\
n=45\end{array}$ & $\begin{array}{l}k=1.905 \\
\mathrm{n}=43\end{array}$ & $\begin{array}{l}k=1.132 \\
\mathrm{n}=88\end{array}$ & 48.8 \\
\hline 1999 (2) & 30 & $\begin{array}{l}k=\mathbf{0 . 5 9 1} \\
\mathrm{n}=60\end{array}$ & $\begin{array}{l}k=\mathbf{0 . 5 0 4} \\
\mathrm{n}=21\end{array}$ & $\begin{array}{l}k=\mathbf{0 . 6 0 4} \\
\mathrm{n}=81\end{array}$ & $25.9 \ddagger$ \\
\hline Total 1999 & 68 & $\begin{array}{l}k=\mathbf{0 . 6 5 0} \\
\mathrm{n}=105\end{array}$ & $\begin{array}{l}k=1.015 \\
\mathrm{n}=64\end{array}$ & $\begin{array}{l}k=\mathbf{0 . 8 2 1} \\
\mathrm{n}=169\end{array}$ & $37.8 \dagger$ \\
\hline Pooled & 233 & $\begin{array}{c}k=\mathbf{0 . 7 3 5} \\
\mathrm{n}=304\end{array}$ & $\begin{array}{l}k=\mathbf{0 . 7 8 5} \\
\mathrm{n}=316\end{array}$ & $\begin{array}{l}k=\mathbf{0 . 8 1 5} \\
\mathrm{n}=620\end{array}$ & 50.9 \\
\hline
\end{tabular}

* Values of $k$ in bold indicate a significant aggregation of louse flies. $\dagger P<0.01$

$\ddagger P<0.001$ for sex ratios differing from 1:1 through goodness-of-fit tests.

tion between parasite prevalence and level of aggregation. Additionally, both prevalence and $k$-values for ectoparasites are higher in colonial than in territorial birds (Rékási et al., 1997).

Avian coloniality facilitates horizontal transmission of parasites (Rózsa et al., 1996; Rékási et al., 1997) that may reduce their aggregation (Poulin, 1998). However, some louse-fly species do not move easily between hosts (Marshall, 1981a), which may explain the lack of differences in the abundance of louse flies between solitary and group-living passerines (Poulin, 1991). Wingless Crataerina flies are mainly vertically transmitted from parent hosts to offspring in the nests (Lee and Clayton, 1995), but they are also known to move actively between nests (Summers, 1975). In fact, Roulin et al. (1998) found frequent movements of $C$. melbae between nests of alpine swifts, and all nests $(n=58)$ in their study were parasitized by the flies. Because nests of alpine swifts in our colony were clumped in small crevices, flies probably moved from nest to nest, as observed by Roulin et al. (1998). Therefore, coloniality may be the reason for high louse-fly prevalence and low degree of aggregation on alpine swifts compared to infestation in other bird species.

\section{Sources of variability on louse-fly aggregation}

The degree of aggregation of louse flies varied among sampling dates and years, and the overall aggregation was exaggerated when pooling all data. This observation supports Shaw
TABLE II. Generalized linear models explaining the number of males, number of females, and total number of louse flies parasitizing individual alpine swifts using Poisson error and logarithm link function.

\begin{tabular}{lccc}
\hline & $\begin{array}{c}\text { Parameter } \\
\text { estimate }\end{array}$ & $\begin{array}{c}\text { Standard } \\
\text { error }\end{array}$ & $P$ \\
\hline Number of males & & & \\
Constant & 0.9240 & 0.1298 & \\
Number of females & 0.1591 & 0.0123 & $<0.001$ \\
& & & \\
Number of females & & & \\
Constant & -0.9980 & 0.2248 & \\
Number of males & 0.1950 & 0.0148 & $<0.001$ \\
Date & 0.0417 & 0.0072 & $<0.001$ \\
Year 1992 & 0.5730 & 0.2148 & $<0.005$ \\
Year 1998-1999 & 0.3870 & 0.2192 & $<0.005$ \\
Total number of louse flies & & & \\
Constant & 0.7704 & 0.1008 & \\
Year 1992 & 0.6120 & 0.1806 & $<0.005$ \\
\hline
\end{tabular}

et al. (1998), who indicated that parasite distributions obtained from a single sample of hosts (e.g., Stewart et al., 1996) may not be representative of the particular host-parasite system as a whole. Interestingly, we also found variability in parasite ag-
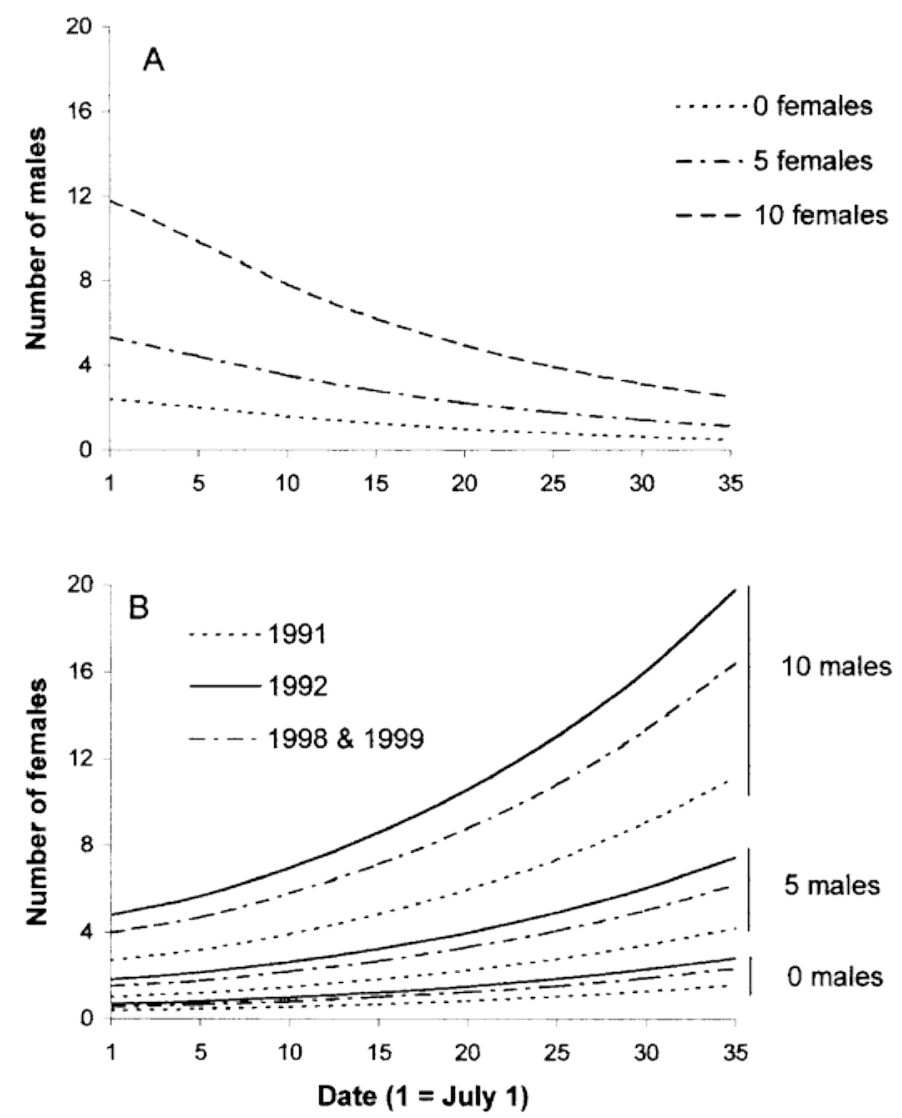

FIgURE 2. Number of male (A) and female (B) louse flies parasitizing individual adult alpine swifts in relation to date of sampling, years, and number of flies of the opposite sex. Fitted lines are obtained from the GLMs of Table II. 
gregation between male and female louse flies, suggesting differential sex-related dynamics of louse flies parasitizing adult swifts (see below).

Many sources of variability, i.e., seasonality, the distribution of infective stages, and individual host characteristics, have been proposed to explain the variability in parasite aggregation (Shaw et al., 1998). Our GLM, based on the number of louse flies on individual hosts, showed only differences between years. These are probably related to variations in weather conditions between years that are known to affect the overall abundance of louse flies (Marshall, 1981a; Senar et al., 1994). Interestingly, none of the individual host characteristics that usually are considered as the main sources of variability for parasite aggregation (Poulin, 1998) entered into the GLM. We previously showed that the mean abundance of $C$. melbae was higher in adult than in second-year alpine swifts using pooled data from all years (Tella et al., 1995). This age effect was also significant at the individual host level in the first step of the GLM modeling but disappeared when controlling for year. On the other hand, these results confirm our previous finding that there is no relationship between the host's body condition and their parasite burdens (Tella et al., 1995). Body size, molt stage, and sex of hosts, factors usually not considered when dealing with louse flies, did not explain the parasite burdens. Finally, the potential effect of the distribution of infective stages between nests (Shaw et al., 1998) could not be tested here. Although all nests of alpine swifts studied by Roulin et al. (1998) were parasitized, louse-fly numbers varied greatly between them (2-55 flies). Because the tarsi and necks of the alpine swift are stiff (Cramp, 1985), which may be a handicap for adequate preening and scratching, most variability in louse-fly burdens on individual adults could be explained by variability in louse-fly loads in their nests. That could explain why our GLM, including year effects, accounted only for $5.5 \%$ of the total deviance.

\section{Sex-related aggregation of louse flies}

Although, as discussed above, the heterogeneity in the number of flies among nests could account for its aggregation on adult swifts, the GLMs performed for each louse-fly sex indicated a new source of aggregation. The number of males as well as the number of females parasitizing a swift were unrelated to any host characteristics. However, both numbers were positively correlated, i.e., the number of flies of one sex tended to increase with the number of the opposite sex on the same bird. This result was strong even though the number of females, but not males, changed between years, and both numbers changed during the breeding season but in opposite ways (Fig. 2). All of these facts make it unlikely that equal numbers of males and females occur on a single host at the same time. Therefore, it seems that sexual attraction could be the proximal cause of the aggregated distribution of louse flies in adult alpine swifts. To our knowledge, mate attraction has never been proposed as a cause of parasite aggregation (Poulin, 1998; Shaw et al., 1998). This novel possibility makes sense for louse flies, because these parasites use the body of adult hosts for mating and copulation (Marshall, 1981a). Our results, however, do not allow us to distinguish which sex seeks out the other, or whether there might be mutual sex attraction.

\section{Interpreting sex-ratio variability in louse flies}

The opposite sex-related seasonal patterns in the numbers of C. melbae explained the sex-ratio decrease as the breeding season advanced, a previously unresolved question posed by Hutson (1981) after finding a seasonal decrease in the sex ratio of C. pallida on adult European swifts. There is no clear explanation for the sex-related seasonal change in the numbers of louse flies, but some hypotheses can be advanced. First, male louse flies are slightly smaller than females and could be more easily overlooked (Marshall, 1981a), but sampling biases related to sex and season are negligible in our collecting protocol. Second, although sex ratio of louse flies at emergence is usually 1:1, males may emerge and die earlier than females (Marshall, 1981a). Finally, differential activity of males and females could also play a role. Female louse flies seem to spend less time on the host and more in the nest (where puparia are deposited) than males (Marshall, 1981a), and thus the use of swift bodies by one sex or the other could change during the breeding cycle of the flies.

Whatever the mechanisms explaining sex-related changes in the number of louse flies, our results indicate that the date of sampling should be considered when studying their sex ratios. Whereas the overall sex ratio of $C$. melbae did not differ from unity, very different perspectives may be obtained depending on the date of sampling. Thus, some of the skewed sex ratios previously reported for louse-fly species (Marshall, 1981a; Hutson, 1981) may have been the result of date-biased sampling.

Finally, the variability in the sex ratio of C. melbae on individual swifts was not related to characteristics of the host, some of which (size, mass, body condition) could stimulate local resource competition in louse flies because male flies are smaller than females (Marshall, 1981a). Moreover, the number of louse flies parasitizing a swift was also unrelated to their sex ratio, thus discarding both the local resource and local matecompetition hypotheses (Rózsa et al., 1996) for C. melbae on alpine swifts. The simultaneous study of $C$. melbae in both adult swifts and their nests, including experimental work, are desirable for a better understanding of this particular host-parasite system. Due to the cliff-nesting habits of alpine swifts, this next step would be feasible only in exceptional places were nests are accessible (Roulin et al., 1998).

\section{ACKNOWLEDGMENTS}

Field work could not have been done without the help of many friends, especially R. López, A. Gajón, C. Gortá zar, J. Blasco, and D. Serrano. During the write-up, J.L.T. was supported by a postdoc from the Spanish Ministry of Science. The suggestions made by G. W. Esch, A. J. Green, and 2 anonymous referees greatly improved the manuscript.

\section{LITERATURE CITED}

Bush, A. O., K. D. Lafferty, J. M. Lotz, and A. W. Shostak. 1997. Parasitology meets ecology on its own terms: Margolis et al. revisited. Journal of Parasitology 83: 575-583.

Clayton, D. H. 1991. The influence of parasites on host sexual selection. Parasitology Today 7: 329-334.

, AND J. MoORE. 1997. Host-parasite evolution. General principles \& avian models. Oxford University Press, Oxford, U.K., 473 p. 
Cramp, S. 1985. The birds of the western Palearctic, Vol. 4. Oxford University Press, Oxford, U.K., 960 p.

Crawley, M. J. 1993. GLIM for ecologists. Blackwell Scientific Publications, Oxford, U.K., 495 p.

Ellegren, H. 1996. First gene on the avian W chromosome (CHD) provides a tag for universal sexing of non-ratite birds. Proceedings of the Royal Society of London, Series B 263: 1635-1641.

Hamilton, W. D., AND M. ZuK. 1982. Heritable true fitness and bright birds: A role for parasites? Science 218: 384-387.

Hudson, P. J., AND A. P. Dobson. 1997. Host-parasite processes and demographic consequences. In Host-parasite evolution. General principles and avian models, D. H. Clayton and J. Moore (eds.). Oxford University Press, Oxford, U.K., p. 128-154.

Hutson, A. M. 1981. The population of the louse-fly, Crataerina pallida (Diptera, Hippoboscidae) on the European swift, Apus apus (Aves, Apodidae). Journal of Zoology, London 194: 305-316.

JaEnIKE, J. 1996. Population-level consequences of parasite aggregation. Oikos 76: 155-160.

Jenni, L., AND R. WinkLer. 1994. Moult and ageing of European passerines. Academic Press, San Diego, California.

John, J. L. 1997. The Hamilton-Zuk theory and initial tests: An examination of some parasitological criticisms. International Journal for Parasitology 27: 1269-1288.

Lee, P. L. M., and D. H. Clayton. 1995. Population biology of swift (Apus apus) ectoparasites in relation to host reproductive success. Ecological Entomology 20: 43-50.

Marshall, A. G. 1981a. The ecology of ectoparasitic insects. Academic Press, London, U.K.

_. 1981b. The sex ratio in parasite insects. Ecological Entomology 6: $155-174$.

MCCluRE, H. E. 1984. The occurrence of hippoboscid flies on some species of birds in southern California. Journal of Field Ornithology 55: $230-240$.

Miklisova, D., AND M. STANKO. 1997. Negative binomial distribution as a model for fleas on small rodents. Biologia, Bratislava 52: 647652.

Poulin, R. 1991. Group-living and infestation by ectoparasites in passerines. Condor 93: 418-423.

. 1995. Evolutionary and ecological parasitology: A changing of the guard? International Journal for Parasitology 25: 861-862.

— 1998 Evolutionary ecology of parasites: From individuals to communities. Chapman \& Hall, London, U.K., 212 p.

- AND W. L. VICKERY. 1993. Parasite distribution and virulence: Implications for parasite-mediated sexual selection. Behavioral Ecology and Sociobiology 33: 429-436.

RÉKÁSI. J., L. Rózsa, AND B. J. KIss. 1997. Patterns in the distribution of avian lice (Phthiraptera: Amblycera, Ischnocera). Journal of Avian Biology 28: 150-156.

Roulin, A., A.-L. Ducrest, J. Jeanmonod, And L. Broch. 1998. Prévalence et intensité parasitaire d'un Hippoboscide (Diptera) chez les jeunes martinets à ventre blanc Apus melba. Nos Oiseaux 45: 185190.

Rózsa, L., J. RéKÁsi, AND J. Reiczigel. 1996. Relationship of host coloniality to the population ecology of avian lice (Insecta: Phthiraptera). Journal of Animal Ecology 65: 242-248.

Saino, N., S. CAlza, AND A. P. Moller. 1998. Effects of a dipteran ectoparasite on immune response and growth trade-offs in barn swallow Hirundo rustica nestlings. Oikos 81: 217-228.

Senar, J. C., J. L. Copete, J. Domenech, and G. von Walter. 1994. Prevalence of louse-flies (Diptera, Hippoboscidae) parasitizing a cardueline finch and its effect on body condition. Ardea 82: 157160.

Shaw, D. J., B. T. Grenfell, And A. P. Dobson. 1998. Patterns of macroparasite aggregation in wildlife host populations. Parasitology 117: 597-610.

Stewart, I. R. K., F. Clark, and M. Petrie. 1996. Distribution of chewing lice upon the polygynous peacock Pavo cristatus. Journal of Parasitology 82: 370-372.

Summers, R. W. 1975. On the ecology of Crataerina hirundinis (Diptera: Hippoboscidae) in Scotland. Journal of Zoology, London 175: $557-570$.

Tella, J. L., G. Blanco, M. G. Forero, A. Gajón, J. A. Doná zar, and F. HiRAldo. 1999. Habitat, world geographic distribution and embryonic development of hosts explain the prevalence of avian hematozoa at small spatial and phylogenetic scales. Proceedings of the National Academy of Sciences USA 96: 1785-1789.

- A. Gajón, C. Gortá zar, and J. J. Osácar. 1998. High host specifity of Crataerina melbae (Diptera: Hippoboscidae) in a mixed colony of birds. Journal of Parasitology 84: 198-200.

, C. Gortá zar, A. Gajón, and J. J. Osácar. 1995. Apparent lack of effects of a high louse-fly infestation (Diptera, Hippoboscidae) on adult colonial alpine swifts. Ardea 83: 435-439.

- R. Rodríguez-Estrella, And G. Blanco. 2000. Louse flies on birds of Baja California. Journal of Wildlife Diseases 36: 154-156.

Theodor, O., AND H. Oldroyd. 1964. Hippoboscidae. In Die fliegen der palearktischen region, Lieferung 250, E. Linder (ed.). Stuttgart, Germany, p. 41-45.

Tompkins, D. M., T. Jones, and D. H. Clayton. 1996. Effect of vertically transmited ectoparasites on the reproductive success of swifts (Apus apus). Functional Ecology 10: 733-740.

ZAR, J. H. 1984. Biostatistical analysis. Prentice-Hall International, Englewood Cliffs, New Jersey, 718 p. 